\title{
Odour conveys status on cockroaches
}

The evolution of social dominance is thought to require phenotypic traits that convey honest information regarding an individual's status ${ }^{1}$. These 'badges of status' could be communicated by any means, but only avian plumage has been examined and provides equivocal support for the hypothesis ${ }^{2}$. By chemical manipulation of the odour of socially naive male cockroaches (Nauphoeta cinerea) we show that the sex pheromone of males determines rather than reflects status. The individual chemical constituents of the pheromone have contrasting effects on status, but the evolution of the blend that confers dominance may be constrained by contrasting selection pressures resulting from female mate choice.

The male-produced pheromone of $N$. cinerea that attracts females is composed of three compounds: 3-hydroxy-2-butanone, 2-methylthiazolidine and 4-ethyl-2-methoxyphenol $^{3,4}$. The quantities of these are heritable and co-vary with male status ${ }^{5,6}$. Female mate choice is based on pheromonal differences among males ${ }^{7,8}$. We manipulated the quantities of these three components

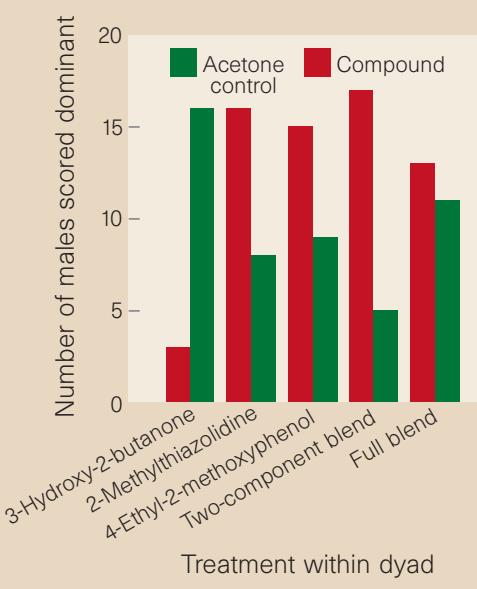

Figure 1 Pairs of males were treated, one with the compound (or mixture) and one with acetone (10 $\mu$ l placed on a filter paper on the pronotum). The experiment was performed blind, with respect to which chemicals were being applied. Males with increased 3-hydroxy-2-butanone were more likely to be treated and act as subordinate (binomial test, $P=0.005)$. In contrast, males with increased 2methylthiazolidine $(P=0.054)$ or 4-ethyl-2-methoxyphenol $(P=0.115)$ were slightly more likely to be treated as and to act dominant. This effect was stronger for males treated with increased 2methylthiazolidine and 4-ethyl-2-methoxyphenol $(P=0.005)$. Increasing the amount of all three compounds in ratios corresponding to the individual manipulations had no effect on status $(P=0.345)$. individually and in combinations to investigate their effect on interactions between males.

Adult males were isolated on emergence, and a filter-paper circle (6 $\mathrm{mm}$ diameter) was glued to the pronotum. The pheromonal profile of males was manipulated by adding individual pheromone components: a combination of the two developmentally and genetically correlated components ${ }^{5,6}$, a blend of all three components, or acetone (control) onto the filter paper. The quantity applied was based on the mean quantity of pheromone isolated from the sternal pheromone glands of dominant males ${ }^{5,6}$. After a 15 -min recovery period, a control male and a manipulated male were placed in an open arena $(17 \times 12 \times 6.5 \mathrm{~cm})$ for observations. The social status of each male was determined on the basis of patterns of agonistic behaviour ${ }^{5-9}$.

Status depended on the specific pheromone manipulation (Fig. 1). When 3hydroxy-2-butanone alone was increased in quantity, males were likely to be treated and to react as subordinates. When either 2methylthiazolidine or 4-ethyl-2-methoxyphenol was increased, there was an increased likelihood of being dominant. This effect was even greater when the quantities of both compounds were increased together. The influence of 3-hydroxy-2butanone is cancelled by the combined effects of 2-methylthiazolidine and 4-ethyl2-methoxyphenol; increasing all three compounds simultaneously did not affect status. Thus, the compounds have individual, additive and contrasting effects on status.

Our manipulations did not result in abnormal behaviour. The direction and intensity of interactions were stable within a one-minute observation period. Manipulated males behaved the same as control males of the same status and there were no obvious differences in the way that males were treated. There were no significant differences in the frequency of aggressive acts by males scored as dominant or the frequency of submissive acts by subordinate males. Highly aggressive acts associated with uncertain initial status, such as grappling, biting and kicking, were no more frequent in those interactions resulting in the manipulated male being scored as dominant as in the interactions where the control male was scored as dominant.

A dual function allows badges of status to be 'honest' signals ${ }^{1,10}$. The sex pheromone of $N$. cinerea may have a dual function, acting in both male-male competition and female mate choice ${ }^{5-9}$. Male-male competition influences mating success in N. cinerea $^{5,9}$ so selection could be expected to increase the quantities of both 2-methylthiazolidine and 4-ethyl-2-methoxyphenol and decrease the quantity of 3-hydroxy-2-butanone. There is no genetic constraint to this pattern of evolution: the quantities of 2-methylthiazolidine and 4-ethyl-2-methoxyphenol are genetically correlated but the quantity of 3hydroxy-2-butanone is genetically independent of these and is presumably free to evolve ${ }^{6}$. However, female $N$. cinerea also use all three components of the sex pheromone to discriminate among males ${ }^{5,6,10}$. Sex differences in either the signal perception or the functions of the signal components can thus maintain variations in this pheromone and its multicomponent structure.

\section{Patricia J. Moore}

Division of Natural Sciences and Mathematics,

Transylvania University,

Lexington, Kentucky 40508, USA

Nancy L. Reagan-Wallin

Division of Math and Sciences,

Kentucky State University,

Frankfort, Kentucky 40601, USA

Kenneth F. Haynes, Allen J. Moore

Department of Entomology,

University of Kentucky, Lexington,

Kentucky 40546-0091, USA

e-mail:ajmoore@pop.uky.edu

1. Dawkins, R. \& Krebs, J. R. in Behavioural Ecology (eds Krebs, J. R. \& Davies, N. B.) 282-309 (Sinauer, Sunderland, MA, 1978). 2. Whitfield, D. P. Trends Ecol. Evol. 2, 13-18 (1987).

3. Sreng, L. J. Chem. Ecol. 16, 2899-2912 (1990).

4. Sirugue, D., Bonnard, O., LeQuere, J.-L., Farine, J.-P. \& Brossut, R. J. Chem. Ecol. 18, 2261-2276 (1992).

5. Moore, A. J., Reagan, N. L. \& Haynes, K. F. Anim. Behav. 50, 191-202 (1995).

6. Moore, A. J. Evolution (in the press)

7. Moore, A. J. Anim. Behav. 36, 303-305 (1988).

8. Moore, A. J. \& Moore, P. J. Evolution 42, 387-391 (1988).

9. Schal, C. \& Bell, W. J. Biol. Behav. 8, 117-139 (1983)

10. Johnstone, R. A. \& Norris, K. Behav. Ecol. Sociobiol. 32, 127-134 (1993)

\section{Anandamide may mediate sleep induction}

We report here that oleamide, a putative sleep factor ${ }^{1}$, and anandamide, an endogenous cannabinoid ligand $d^{2,3}$, cause similar pharmacological effects in mice. Only anandamide binds to the cannabinoid $\mathrm{CB}_{1}$ receptor but by inhibiting the enzyme which inactivates anandamide (thus increasing its concentration), oleamide potentiates anandamide binding to $\mathrm{CB}_{1}$ enhancing anandamide effects in mice. Our observations raise the possibility that some oleamide effects (including induction of sleep) may be mediated by anandamide.

Cravatt et al. identified and reported the sleep-inducing properties of oleamide, a lipid found in the cerebrospinal fluid of 
sleep-deprived cats ${ }^{1}$; and we have isolated and characterized anandamide, a lipid from the brain which is an agonist for the cannabinoid receptor ${ }^{2,3}$. Drowsiness or sleepiness are well-known effects in the later stages of intoxication by marijuana, whose active constituent, $\Delta^{9}$-tetrahydrocannabinol ( $\Delta^{9}$-THC), and anandamide have a close biochemical and behavioural profile. Both substances bind to the brain cannabinoid receptor, $\mathrm{CB}_{1}$ (refs 2-4).

The sleep-producing properties of anandamide are not known, but Santucci et $a l^{5}$ have found that the $\mathrm{CB}_{1}$ antagonist SR141716A increases the time spent awake at the expense of both slow-wave and rapideye-movement sleep. They suggested that “...an endogenous cannabimimetic (anandamidergic?) system may regulate the organization of the sleep-waking cycle".

To establish whether there is any relationship between anandamide and oleamide we compared their in vivo and in vitro effects. We examined oleamide in four assays commonly used together for testing cannabinoid (including anandamide) activity $^{3,6}$ : the ring immobility (catalepsy) mice remain motionless; the open-field test, which measures locomotor activity; hypothermia; and response to a hot plate (antinociception). The median effective doses $\left(\mathrm{ED}_{50}\right.$ values) obtained from these tests (Table 1) show that oleamide has essentially the same activity profile as anandamide, though it is less potent in most tests. Testing anandamide in the presence of $7.5 \mathrm{mg}$ oleamide per $\mathrm{kg}$ body mass (Table 1) showed that oleamide potently increased anandamide activity. But oleamide is not a cannabinoid, as even at $10 \mu \mathrm{M}$, it did not bind to $\mathrm{CB}_{1}$, confirming a previous report ${ }^{7}$.

The enzyme responsible for anandamide inactivation, fatty-acid amide hydrolase (FAAH), recognizes oleamide as a substrate $^{8}$, and its molecular characterization, cloning and expression have been reported recently ${ }^{9}$. Using the assays described in refs 8 and 10, we found that oleamide inhibited FAAH-mediated hydrolysis of $\left[{ }^{14} \mathrm{C}\right]$ anandamide by mouse neuroblastoma $\mathrm{N}_{18} \mathrm{TG}_{2}$ cells in a dose-dependent manner (Fig. 1a). With the $10,000 \mathrm{~g}$ particulate fraction, which contains most of the cell $\mathrm{FAAH}^{8}$, the effect was significant at an oleamide concentra-

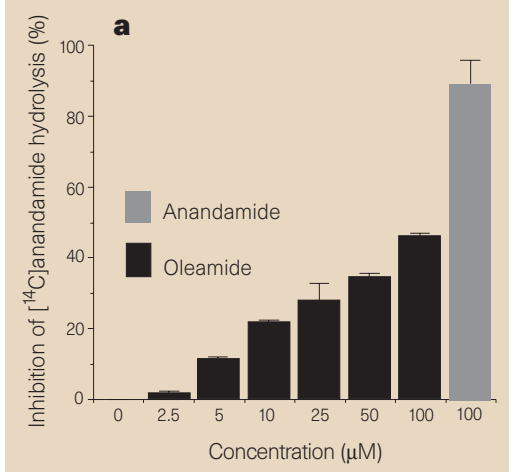

b

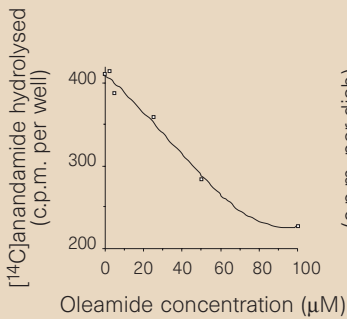

c

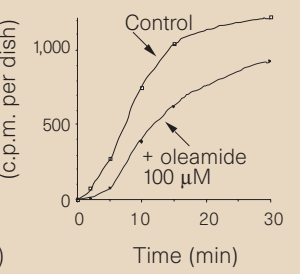

Figure 1 a, Dose-dependent inhibition of $\left[{ }^{14} \mathrm{C}\right]$ anandamide hydrolysis by N18TG2 cell 10,000 $\mathrm{g}$ particulate fractions. b, Dose-dependent inhibition of [ $\left.{ }^{14} \mathrm{C}\right]$-anandamide hydrolysis by intact confluent N18TG2 cells. c, Effect of $100 \mu \mathrm{M}$ oleamide on time-dependent $\left[{ }^{1} \mathrm{C}\right]$ anandamide hydrolysis by intact confluent N18TG2 cells. The breakdown of $\left[{ }^{14} \mathrm{C}\right]$ anandamide was measured from the $\left[{ }^{14} \mathrm{C}\right]$ ethanolamine released by hydrolysis of the amide bond in anandamide as described previously ${ }^{10}$. Data in $\mathbf{a}$ are means \pm s.e.m of three separate experiments. Data in $\mathbf{b}$ and $\mathbf{c}$ are means of duplicates, representative of three experiments. test, which measures the percentage of time

tion of $5 \mu \mathrm{M}$, with $48 \%$ inhibition with 100 $\mu \mathrm{M}$ oleamide. This effect was smaller than that obtained with anandamide (90\% inhibition with $100 \mu \mathrm{M}$ ), in agreement with previous observations that FAAH catalyses the hydrolysis of anandamide more rapidly than that of oleamide ${ }^{8,9}$.

With intact cells, the inhibitory effect of oleamide was dose-dependent, producing marked elevations in $\left[{ }^{14} \mathrm{C}\right]$ anandamide levels (Fig. 1b). When $\left[{ }^{14} \mathrm{C}\right]$ anandamide $(50 \mu \mathrm{M})$ and oleamide $(100 \mu \mathrm{M})$ were coincubated, there was a $75-100 \%$ inhibition of $\left[{ }^{14} \mathrm{C}\right]$ anandamide hydrolysis with short incubation times (2-5 min; Fig. 1c), under which conditions the physiological activation of $\mathrm{CB}_{1}$ receptors by anandamide is likely to occur.

We also tested the ability of oleamide to affect the $K_{\mathrm{i}}$ of anandamide in competition binding experiments (against $\left[{ }^{3} \mathrm{H}\right] \mathrm{HU}-243$, a high-affinity cannabinoid ligand ${ }^{2}$ ) to $\mathrm{CB}_{1}$ in transfected COS-7 cells ${ }^{11}$. Anandamide alone yielded a $K_{\mathrm{i}}$ of $350 \pm 7 \mathrm{nM}$. In the presence of the amidase inhibitor phenylmethylsulphonyl fluoride (PMSF; $200 \mu \mathrm{M}$ ) the observed $K_{\mathrm{i}}$ decreased by roughly one order of magnitude. A similar enhancement in affinity was seen on addition of oleamide $(50 \mu \mathrm{M})$. With PMSF and oleamide together, the affinity did not increase any further.

Naturally occurring oleoylethanolamide (the oleic acid analogue of anandamide),

\begin{tabular}{|c|c|c|c|c|}
\hline \multicolumn{5}{|c|}{ Table 1 Behavioural effects of $\Delta^{9}$-THC, anandamide and oleamide } \\
\hline \multirow[b]{2}{*}{ Test } & \multirow[b]{2}{*}{$\Delta^{9}-\mathrm{THC}$} & \multicolumn{2}{|c|}{$\mathrm{ED}_{50}$ values } & \multirow[b]{2}{*}{ Anandamide + oleamide } \\
\hline & & Anandamide & Oleamide & \\
\hline Open field (ambulation) & 7.0 & 3.4 & 5.7 & 0.8 \\
\hline Ring immobility & 2.3 & 5.0 & 18.9 & 2.9 \\
\hline Hypothermia & 9.5 & 3.6 & 17.5 & 1.5 \\
\hline Hot plate & 10.3 & 28.0 & 29.2 & 3.0 \\
\hline \multicolumn{5}{|c|}{$\begin{array}{l}\text { Ten minutes after intraperitoneal injection, mice were tested in four ways to evaluate cannabinoid-induced effects } \\
\text { For each drug, dose-response curves were obtained using } 5-7 \text { doses in the range } 1-10 \mathrm{mg} \text { per } \mathrm{kg} \text { body mass } \\
\text { ( } n=4-7 \text { mice for each dose). } \mathrm{ED}_{50} \text { values were calculated by nonlinear regression (Graphpad Prism). } \\
\text { Anandamide + oleamide denotes anandamide in the presence of } 7.5 \mathrm{mg} \text { oleamide per } \mathrm{kg} \text { body mass. }\end{array}$} \\
\hline
\end{tabular}

the hybrid structure between anandamide and oleamide, also fails to activate $\mathrm{CB}_{1}$ (ref. 12), but has similar effects to oleamide in mice (unpublished results) and inhibits anandamide hydrolysis in rat brain microsomes ${ }^{12}$.

Our observations, together with previous results, raise the possibility that some oleamide effects (including induction of sleep) may be mediated by anandamide.

\section{Raphael Mechoulam}

Ester Fride

Lumir Hanuš

Tzviel Sheskin

Department of Natural Products,

David Bloom Centre for Pharmacy,

Faculty of Medicine, Hebrew University,

Jerusalem 91120, Israel

e-mail:Mechou@yam-suff.cc.huji.ac.il

\section{Tiziana Bisogno}

Vincenzo Di Marzo

Istituto per la Chimica di Molecole

di Interesse Biologico,

Via Toiano 6, 80072 Arco Felice,

Naples, Italy

Michael Bayewitch

Zvi Vogel

Department of Neurobiology,

Weizmann Institute of Science,

Rehovot 76100, Israel

1. Cravatt, B. F. et al. Science 268, 1506-1509 (1995)

2. Devane, W. A. et al. Science 258, 1946-1949 (1992).

3. Fride, E. \& Mechoulam, R. Eur. J. Pharmacol. 231, 313-314 (1993).

4. Piomelli, D. Arachidonic Acid in Cell Signaling 167-195 (Landes Co., Austin, 1996).

5. Santucci, V., Storme, J. J., Soubrie, P. \& Le Fur, G. Life Sci. 58, 103-110 (1996).

6. Martin, B. R. et al. Pharmacol. Biochem. Behav. 40, 471-478 (1991).

7. Boring, D. L., Berglund, B. A. \& Howlett, A. C. Prostaglandins Leukot. Essent. Fatty Acids 55, 207-210 (1996).

8. Maurelli, S. et al. FEBS Lett. 277, 82 (1995).

9. Cravatt, B. F. et al. Nature 384, 83-87 (1996).

10. Di Marzo, V. et al. Nature 372, 686-691 (1994).

11. Vogel, Z. et al. J. Neurochem. 61, 352-355 (1993).

12. di Tomaso, E., Beltramo, M. \& Piomelli, D. Nature 382, 677-678 (1996). 